\title{
Seismic activity near the Moriyoshi-zan volcano in Akita Prefecture, northeastern Japan: implications for geofluid migration and a midcrustal geofluid reservoir
}

\author{
Masahiro Kosuga
}

\begin{abstract}
The 2011 off the Pacific coast of Tohoku (Tohoku-oki) earthquake caused increased seismicity in many inland areas in Japan. A seismic cluster north of the Moriyoshi-zan volcano in Akita prefecture, Tohoku District, is of interest in light of the contribution of geofluids to seismic activity. We observed a seismic cluster characterized by the migration of seismicity and reflected/scattered phases. We relocated hypocenters of the cluster using data from temporal observations and the hypoDD location technique, which significantly increased the hypocentral accuracy. We interpreted a complex spatiotemporal variation of seismicity in the cluster as the migration of pore fluid pressure from multiple pressure sources. The hydraulic diffusivity of the cluster was in the range of 0.01 to $0.7 \mathrm{~m}^{2} / \mathrm{s}$ and increased with time, implying that the migration of hypocenters accelerated after a pathway for fluids was formed by fracturing of the wall rock during the initial stage of seismic activity. A prominent feature of the seismograms is a reflected/scattered phase observed at stations around the volcano. We regard the phase as S-to-S scattered waves and estimated the location of the scatterers using a back-projection method. The scatterers are inferred to be located about $5 \mathrm{~km}$ northwest of the Moriyoshi-zan volcano, at an approximate depth of $13 \mathrm{~km}$. The Moriyoshi-zan area is one of the source areas of deep low-frequency earthquakes that have been interpreted as events generated by the migration of geofluids. The depth of the scatterers is close to the upper limit of the depth at which low-frequency earthquakes occur. Thus, we interpret the observed scatterers to be a reservoir of geofluid that came from the uppermost mantle accompanying contemporaneous low-frequency earthquakes.
\end{abstract}

Keywords: The 2011 off the Pacific coast of Tohoku earthquake; Triggered seismicity; Hypocenter migration; Scattering, Geofluid

\section{Background}

The 2011 off the Pacific coast of Tohoku earthquake $\left(M_{\mathrm{W}} 9.0\right)$ induced a tsunami that struck along the coast from the Tohoku to Kanto Districts on Honshu Island, Japan, causing indescribable, severe damage. This megathrust earthquake, with a fault length of up to $500 \mathrm{~km}$ along the Japan Trench, brought significant seismicity changes in areas far from the source fault. Hirose et al. (2011) comprehensively investigated the change in seismic activity generated by this earthquake and observed increased activity in many areas from Hokkaido to Kyushu,

Correspondence: mkos@cc.hirosaki-u.ac.jp

Earthquake and Volcano Observatory, Graduate School of Science and Technology, Hirosaki University, Hirosaki 036-8561, Japan in particular, in and around the Kanto District. They noted that areas of triggered seismicity tend to be distributed along the volcanic front, and that the start time of seismic activity in different areas is variable. Many researchers have investigated the characteristics of triggered seismic activity in the areas around the Kanto District (Ishibe et al. 2011; Yukutake et al. 2011a), along the eastern coast from Ibaraki to Fukushima Prefectures (Kato et al. 2011; Imanishi et al. 2012), and the Tohoku region (Okada et al. 2011; Kosuga et al. 2012; Terakawa et al. 2013; Okada et al. 2014). The observed seismicity may be triggered by the dynamic effect of the seismic wave of the mainshock (Miyazawa 2011, 2012), by the static effect of crustal deformation caused by megathrust faulting (Kato et al. 2011; 
Kosuga et al. 2012), and by weakening of inland faults due to the associated increase in pore fluid pressure (Okada et al. 2011; Terakawa et al. 2013).

In northern Tohoku District, triggered seismicity was observed to be significantly higher in Akita Prefecture, located on the Japan Sea side of the island. Figure 1a compares the activity before and after the Tohoku-oki earthquake. We observed three major post-seismic clusters in Akita Prefecture. Seismic activity in the northern part of Akita Prefecture (Figure 1b) started about 2 months after the Tohoku-oki earthquake and cannot be explained by either dynamic or static changes in the stress field. Thus, the activity in the area around the Moriyoshi-zan volcano is quite interesting in the light of the contribution of geofluids to seismic activity. There are some additional observations that suggest a contribution of geofluids to the observed anomalous seismic activity. First, seismic activity showed hypocenter migration, which has frequently been interpreted as fluid-driven activity (e.g.,
Shapiro et al. 1997). Second, the reflected/scattered phase observed in the seismograms also suggests the presence of geofluids. Third, as shown in Figure 1b, the Moriyoshi-zan area is a source area of deep low-frequency (DLF) earthquakes. Since the DLF earthquakes occur below the depth limit of brittle failure, the earthquakes have been interpreted as events generated by the activity of geofluids (e.g., Hasegawa and Yamamoto 1994). Therefore, this study area is considered suitable for investigating the relationship between seismic activity and geofluids. To do this, accurate information regarding earthquake location is essential. However, there are few permanent seismic stations close to the active cluster near the Moriyoshi-zan volcano (Figure 1b), which may result in poor depth control in the catalog hypocenters. Considering this situation, we deployed temporary seismic stations on September 2012 near the most active cluster.

In this study, we first relocate the hypocenters in the Moriyoshi-zan area using the combined arrival time data

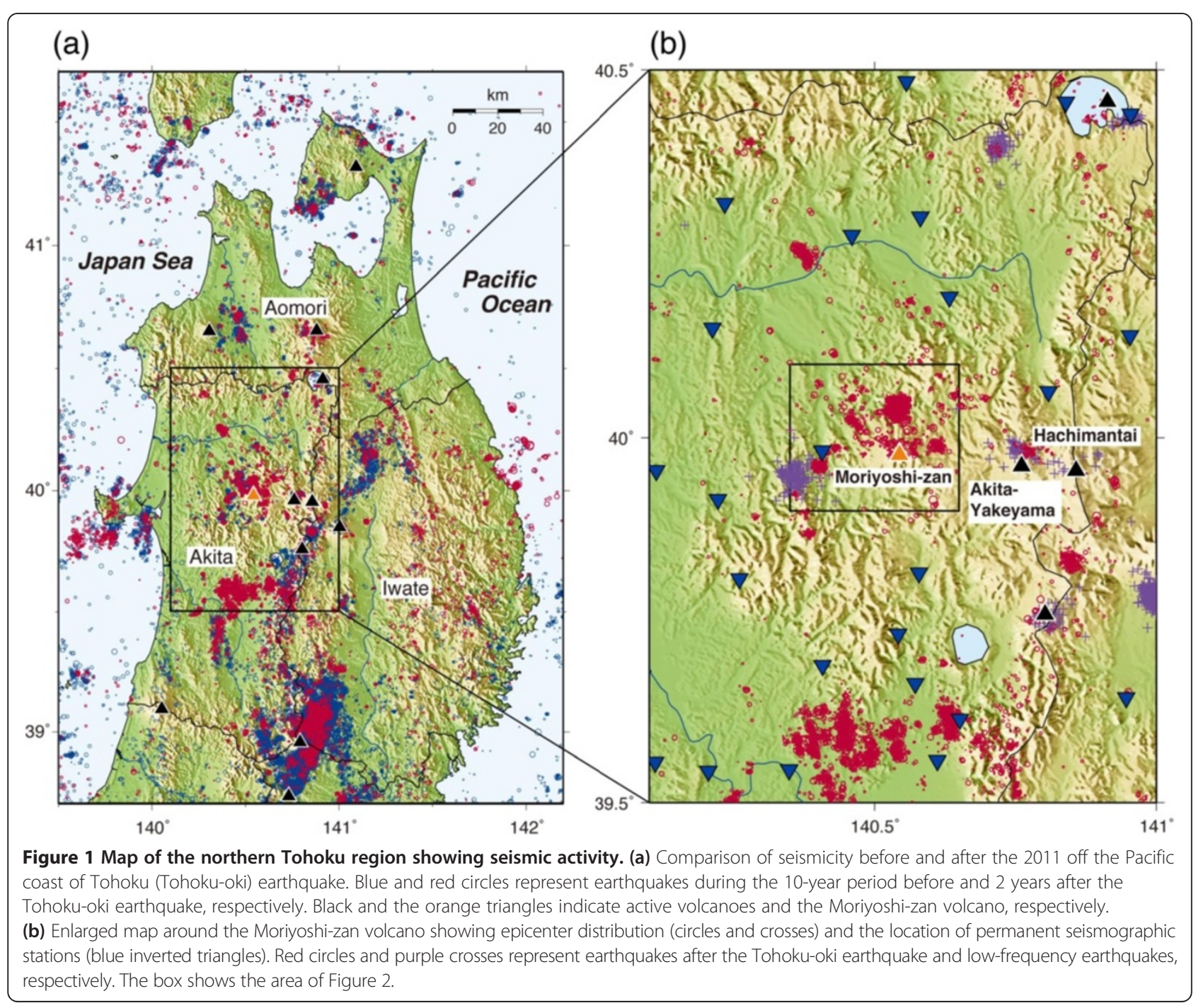


of the permanent and the temporary stations and by employing the hypoDD location technique (Waldhauser and Ellsworth 2000). We then investigate the migration of hypocenters in detail using the relocated hypocenters, considering the accuracy of the hypocenter locations. We interpret the spatiotemporal variation of the hypocenters based on the migration of fluid pressure. The other main purpose of this paper is to examine the source location of scattered waves from the clusters around the volcano. We apply a back-projection method to obtain an image of the strong scattering zone using the average residual root mean square (RMS) envelopes, that is, the difference between the observed and theoretical envelopes. Considering the observations of earthquake migration and the location of scatterers, we discuss the influence of geofluids on seismicity in the Moriyoshi-zan area.

The Moriyoshi-zan is a Quaternary volcano with a height of 1,454 m located about $20 \mathrm{~km}$ west of two active volcanoes, Akita-Yakeyama and Hachimantai, that form the volcanic front running $\mathrm{N}$ to $\mathrm{S}$ in the central part of the Tohoku region (Figure 1b). According to Nakagawa (1983), the volcanic activity of the Moriyoshi-zan volcano can be divided into two stages. In the early stage, which occurred during the middle Pleistocene, pyroclastics with a small amount of lava flow erupted to form a coneshaped stratovolcano, followed by the formation of an ellipse-shaped caldera. In the later stage, lava flows effused, and lava domes extruded near the caldera wall. No volcanic activity is observed at present.

\section{Methods}

Temporary observation in the Moriyoshi-zan area

Figure 2a shows the hypocenter distribution around the Moriyoshi-zan volcano from March 2011 to September 2013 from the catalog of the Japan Meteorological Agency (JMA). Numerous earthquake clusters have been observed around the volcano. Among them, the cluster north of the volcano has been the most active. The size of this cluster is approximately $3 \mathrm{~km}$ both horizontally and vertically. The hypocenter distribution in the cluster is not planar but volumetric, which suggests that no major fault exists within the cluster.

Since there is only one permanent seismic station nearby, approximately $10 \mathrm{~km}$ west of the volcano (N.ANIH in Figure 2), we deployed temporary stations near the most active cluster on September 2012. One of the stations (HR.MRY in Figure 2b) uses a three-component velocity sensor with a natural frequency of $0.2 \mathrm{~Hz}$. The other station (array in Figure 2b) consists of nine three-component velocity sensors with a natural frequency of $1 \mathrm{~Hz}$. The spacing of the array sensors is approximately $150 \mathrm{~m}$. The recording is continuous, with a sampling frequency of $200 \mathrm{~Hz}$ and 24-bit resolution. We installed the array station in order to investigate the wave field of DLF earthquakes. For the purpose of this paper, which is to examine the hypocenter migration and to analyze the later phases from shallow earthquakes, we used just one of the nine sensors of the array.

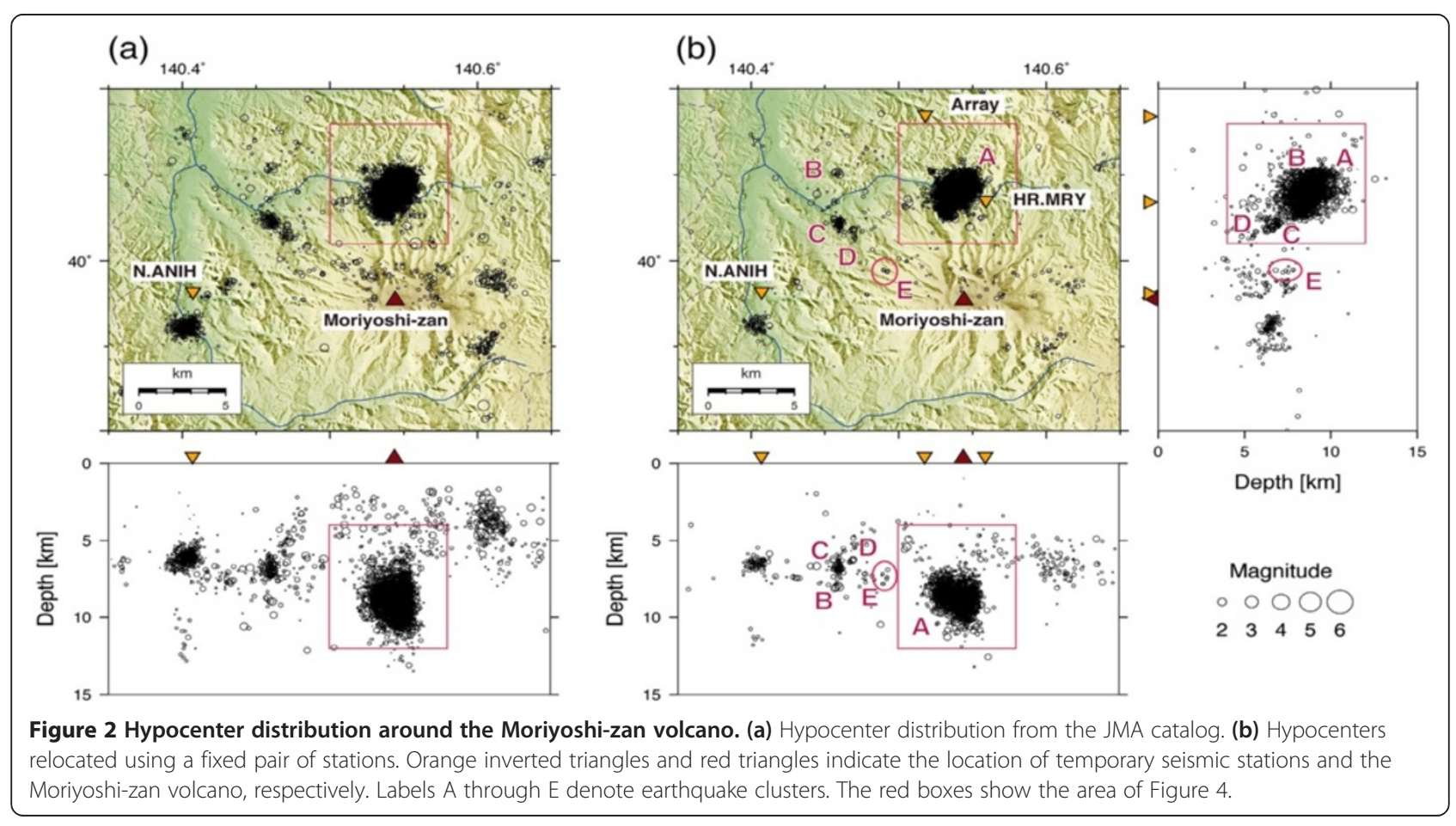




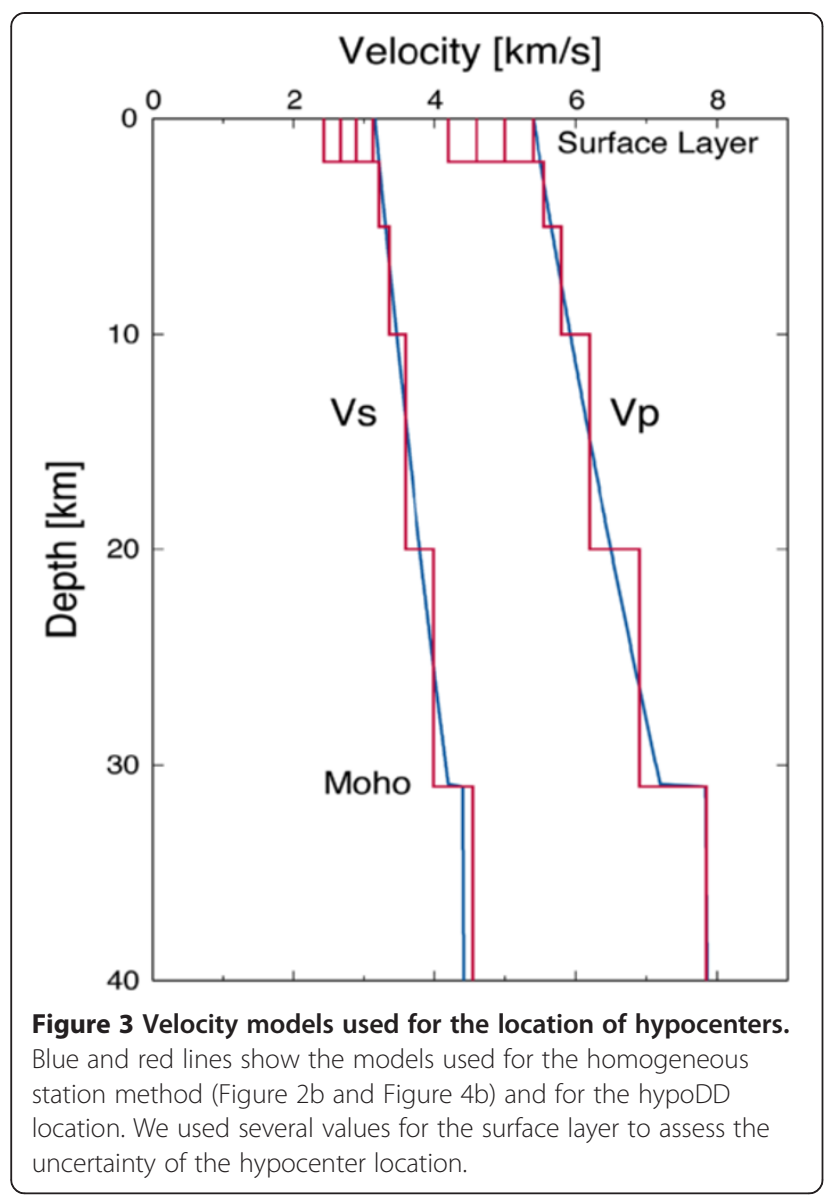

\section{Hypocenter location}

To locate hypocenters, we manually picked the arrival times of $P$ - and $S$-waves for some permanent stations around the volcano (Figure $1 \mathrm{~b}$ ), as well as the temporary stations. Most of the events we picked had magnitudes equal to or greater than 1.0 on the JMA scale. We then relocated and compared the hypocenters using several methods. We used a 1-D velocity structure similar to that used for routine hypocenter location at Tohoku University (Hasegawa et al. 1978, blue lines in Figure 3). Figure 2b shows the hypocenter distribution determined using the arrival times at the seven permanent stations selected by the number of picks, and the two temporary stations. Compared with the catalog locations (a), it is clear that the relocated clusters are tightly concentrated. In the cross section, the depth range of the largest cluster (A) is 7 to $11 \mathrm{~km}$ in the relocation, whereas the depths of the catalog events have a wider range of 6 to $12 \mathrm{~km}$. In addition, the number of events with depths shallower than $5 \mathrm{~km}$ is reduced in the relocated cross section. These observations indicate an increase in hypocentral accuracy. In the cross section, the lower depth limit of seismicity is shallow near the Moriyoshi-zan volcano. The observed aseismic zone forms a conical shape centered at the volcano, though no seismicity is observed south of the volcano. This suggests increased temperatures beneath the volcano.

As mentioned earlier, the migration of hypocenters is characteristic of seismic cluster A. To investigate the cluster's spatiotemporal variation of seismicity in detail, we relocated the hypocenters using the hypoDD location technique (Waldhauser and Ellsworth 2000). This method is based on the idea that if the ray paths between a source region and a station are similar, the difference in travel times for two events can be attributed to the spatial offset between the events. This method determines the absolute and relative locations of a set of events simultaneously. The above assumption is not valid for events that are far apart, which may result in biased event locations due to velocity heterogeneity (Got et al. 1994; Waldhauser and Ellsworth 2000; Wolfe 2002; Zhang and Thurber 2003). Thus, we applied the method only to cluster A. The data we used are both catalog (CT) picks that consist of JMA picks and our picks, as well as crosscorrelation (CC) picks. The CC picks are derived from the cross-spectral method in which the differential travel times are measured between possible pairs of earthquakes with similar waveforms (Poupinet et al. 1984; Ito 1985). We used 139,853 CT and 1,256 CC picks for $P$-waves and $113,902 \mathrm{CT}$ and 2,758 CC picks for $S$-waves. We used the velocity structure shown in Figure 3, with a surface $P$-wave velocity of $5.0 \mathrm{~km} / \mathrm{s}$.

Figure 4 compares the hypoDD locations with those estimated by other methods for the same events. Figure $4 \mathrm{a}$ shows the JMA catalog locations and (b) shows the results of the homogeneous station method, in which we used data from a homogeneous set of stations with seven permanent and two temporary stations. Compared with the catalog locations, the locations in (b) are tightly clustered and are systematically shallower. The results of hypoDD locations in (c) show a much more concentrated hypocenter distribution. The N-S dimension is reduced from approximately $3.4 \mathrm{~km}$ in (b) to $2.8 \mathrm{~km}$, and the average depth is approximately $0.5 \mathrm{~km}$ deeper. The use of CC picks contributed significantly to the tightness of the hypocenter distribution. Thus, the hypoDD locations are the most accurate among the locations in Figure 4.

Although the accuracy of the relative locations was considerably improved by the hypoDD location, we need to know the uncertainty of the absolute locations to investigate the hypocenter migration. The hypoDD routine reported mean 2-sigma errors of 3.1, 3.6, and $5.8 \mathrm{~m}$ in the $x, y$, and $z$ directions, respectively. Since we used the LSQR algorithm to solve a large system, the above error may be underestimated. Therefore, we assessed the error by examining the change in hypocenters caused by changes in the velocity structure and by different combinations of stations. For the velocity structure, we tried four velocity values for the surface layer (Figure 3) that 


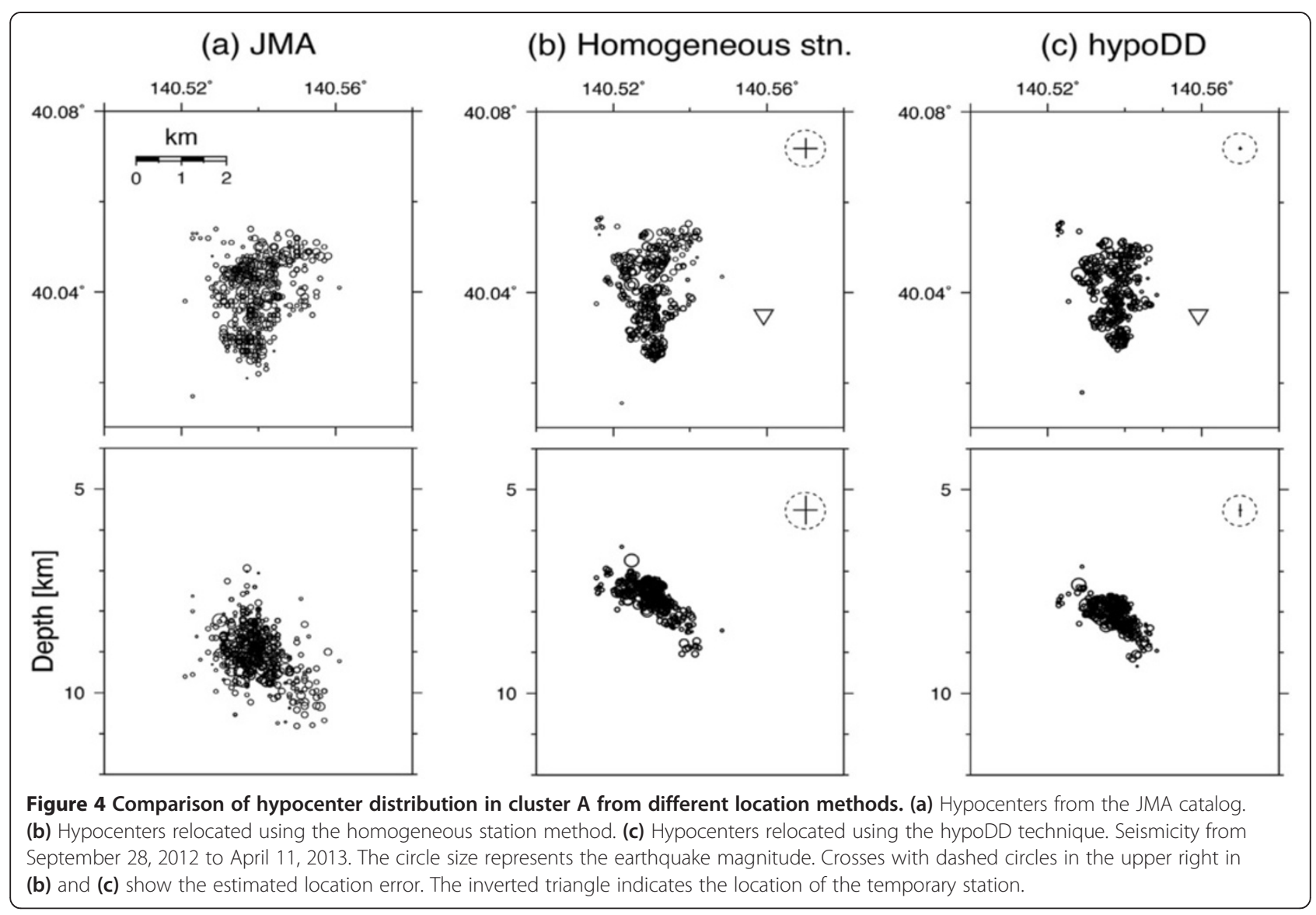

may most affect the hypocenter location. For the station combinations, we obtained hypoDD locations by excluding picks from one of six permanent, and two temporary stations in turn. Figure 5 shows the fluctuation of hypocenters from 11 trials. The colors classify the events. The fluctuation is larger in the vertical direction. The average standard deviation for all the data are 42.7, 40.0, and $156.4 \mathrm{~m}$ in the $x, y$, and $z$ directions, respectively, and is shown at the top right of each panel in Figures 4 and 5. Thus, we regard these values as the location uncertainty, and consider the changes in hypocenter location that exceed these values. The inclined cluster of hypocenters to the east shown in the cross section of Figure 4c appears as a thick slab. This is not due to location uncertainty, but the result of the aggregation of small volumetric clusters, as we can see in the plan view.

\section{Results and discussion}

\section{Migration of seismic activity}

Here, we investigate the spatiotemporal variation of seismicity in cluster A. Figure 6 displays the hypocenter distribution for four periods from May 2011 to September 2013. We divided the period by considering the distance versus time plot in Figure 7a. The hypocentral distance was measured from a deep location of initial activity. There is a gap in activity between the periods (6a) and (6b), a change in gradient of the upper bound of distance versus time from the beginning of the period (6c), and a sudden decrease in the lower bound of distance after the end of the period (6c). In Figure 6, the seismic activity started near the southeast part of the cluster (a) and then migrated to the northeast (b). The activity in the northeastern part continued until August 2012 (c). Then, the activity jumped to the west where many earthquakes occurred, particularly larger events with magnitudes greater than 3.0 (d). During the last period, the hypocenters were scattered across the entire cluster except for the northeastern edge of the cluster. Thus, the spatiotemporal variation of seismicity is not unidirectional but very complex.

In Figure $7 \mathrm{a}$, the upper bound (seismicity front) increases with time, rapidly at first, then gradually. This change in distance reaches $3 \mathrm{~km}$ and is much larger than the hypocenter uncertainty. A parabolic envelope characterizes this diffusion-like front migration. The four curves in Figure $7 \mathrm{a}$ are theoretical predictions for fluid-induced earthquake activity based on the following equation:

$$
r=\sqrt{4 \pi D t}
$$

where $r$ is the distance from the pressure source point, $t$ is the time after the pressure increase, and $D$ is the 


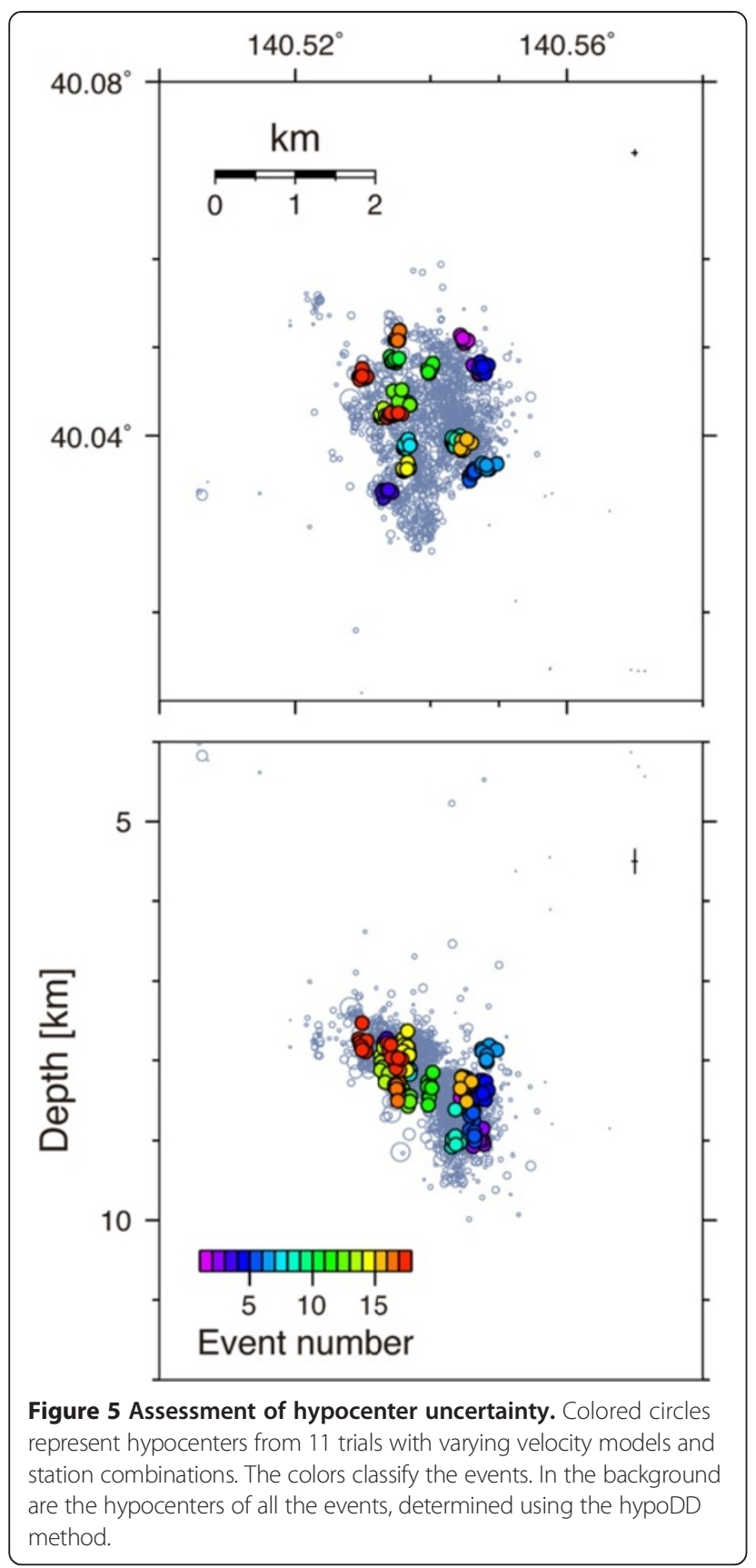

hydraulic diffusivity (Shapiro et al. 1997). In the case of earthquakes triggered by pore pressure diffusion, $r$ is the distance to the front, and the majority of earthquakes are distributed within this distance (Shapiro et al. 1997). For all the events in Figure $7 \mathrm{a}$, in particular in the later stage, a $D$ value of $0.01 \mathrm{~m}^{2} / \mathrm{s}$ is in good agreement with the observed migration rate. However, during the initial stage, a larger $D$ value of 0.05 to $0.1 \mathrm{~m}^{2} / \mathrm{s}$ is considered more appropriate.

As shown in Figure 6, the spatiotemporal variation of seismic activity is very complex, comprising repeated formation of small clusters over brief time periods. Thus, we tried to explain the complex spatiotemporal distribution of seismicity by sequences of seismic migration from multiple pressure sources with variable hydraulic diffusivity. We used the following procedure to estimate four unknown parameters for each pressure source. The parameters are the location of pressure source, time of pressure increase, and hydraulic diffusivity. First, we set a period of curve fitting by specifying a pair of starting and ending events. Because Equation 1 constrains the seismic migration front, we divided the hypocentral data in the period into several time bins and used the event with the greatest distance in each bin for the curve fitting. Next, we performed a grid search to seek the unknown parameters. We set 3-D grids beneath the initial hypocenter, which may be a natural hypothesis to consider the upward migration of geofluids. Best parameters were selected as those with the smallest RMS residual between the observed and estimated distances. We conducted the above procedure by varying the period and obtained a location, time, and residual for every period. Considering the hypocenter accuracy, we performed the fitting if the distance change in the period exceeds $300 \mathrm{~m}$, which is approximately twice the size of the absolute error ellipsoid of the hypoDD location. Finally, we selected the sequences in increasing order of RMS residuals, avoiding sequences whose periods overlap with those previously selected. We checked the range of distance changes for the selected sequences and found that the range was much larger than $300 \mathrm{~m}$ in most cases.

Figure 7b,c,d displays two examples of the selected sequences. The locations of the pressure sources, as well as the data events, are represented in (b), and distance versus time plots are shown in (c) and (d). The $D$ values for the two cases are 0.587 and $0.288 \mathrm{~m}^{2} / \mathrm{s}$. Figure 8 shows the spatiotemporal variation of the diffusivity plotted at the location of the pressure sources (a) and at the origin times (b). In Figure 8a, there are two major clusters of earthquakes; one is the deep cluster located in the east and the other is the shallow cluster located in the west. In the E-W cross section, we can see two rows of pressure sources aligned subhorizontally. The lower sources seem to penetrate the deeper earthquake cluster. The upper sources are located in the gap of seismicity between the shallow and deep clusters. The diffusivity is smaller inside and close to the clusters and larger outside and towards the west. These characteristics might be a clue to understanding the seismogenesis in the area; however, the spatial resolution is still insufficient for both the earthquakes and pressure sources. A promising approach to improve the resolution is an analysis of a larger number of events, including smaller earthquakes that we have not analyzed in this paper. For that purpose, a method by Rowe et al. (2002a, 2002b) is effective. The technique uses 


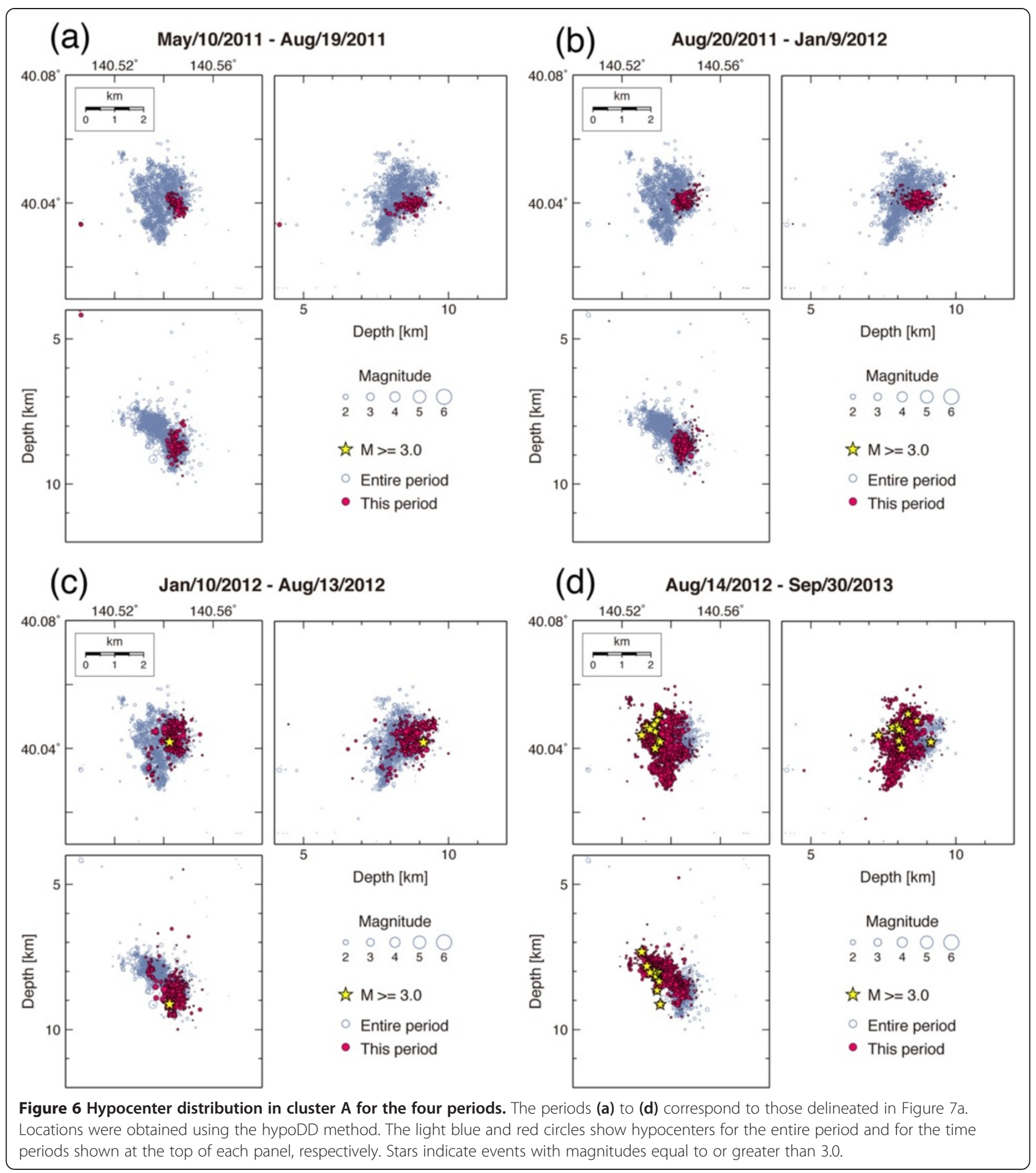

eigenspectral methods for cross-spectral phase estimation, cross-coherency-based filtering, and a hierarchical waveform stack correlation method. It can be inferred from the time plot (Figure 8b) that the diffusivity seems to increase with time, with the maximum diffusivity measured in November 2012, when seismic activity had increased drastically (Figure 6d). The general temporal trend of diffusivity implies that the migration of hypocenters was accelerated after a pathway for fluids was formed by fracturing of the wall rock during the initial stage of seismic activity.

\section{Scattered waves}

A prominent feature of the seismograms from the clusters near the Moriyoshi-zan volcano is a phase labeled $X$ in 

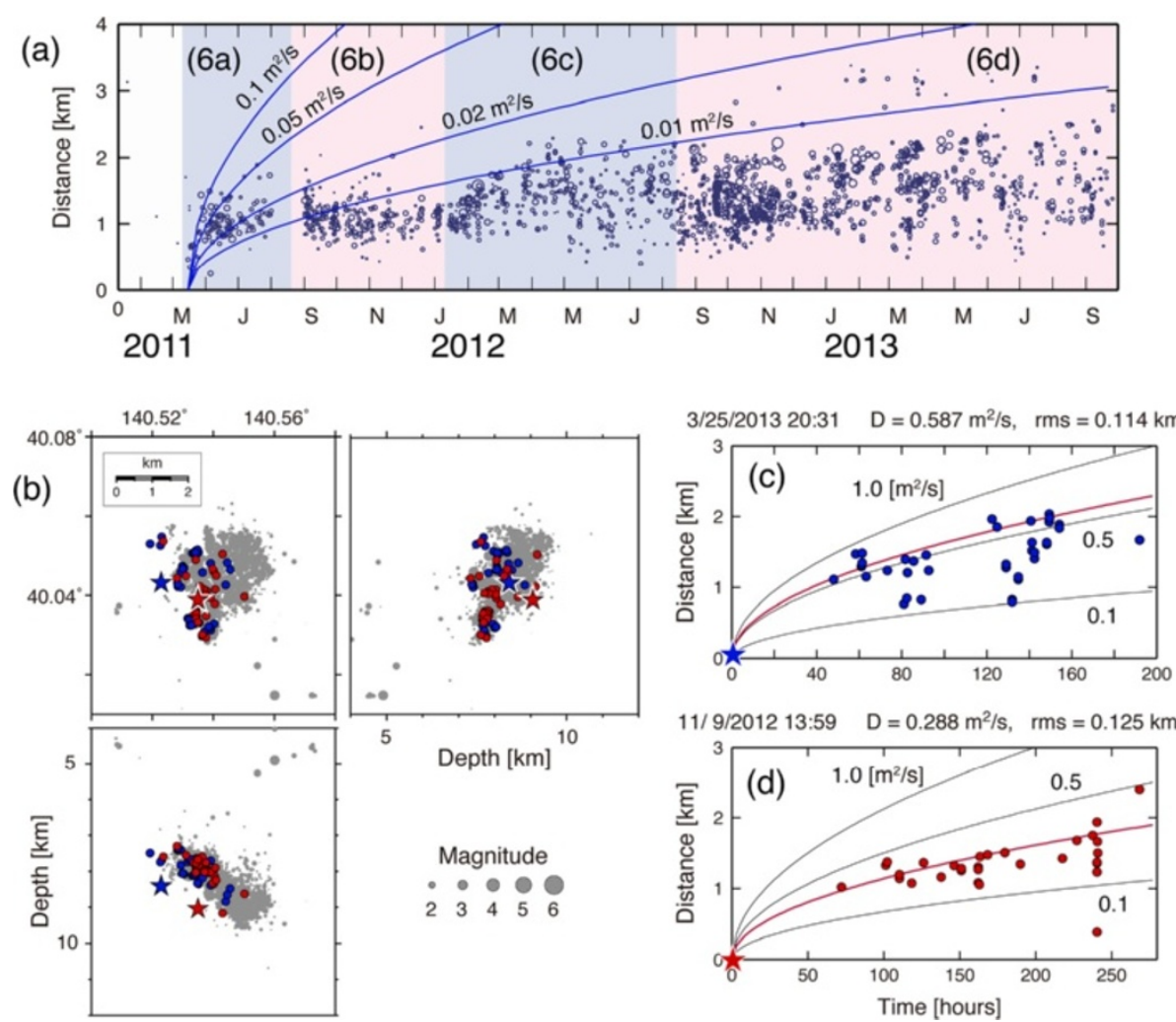

Figure 7 Spatiotemporal variation of seismicity in cluster A. (a) Distance versus time plot for cluster A. We measured the distance from the deep part of initial seismic activity in May 2011. The four curves shown indicate the theoretical position of the propagating pore pressure front for the cases of hydraulic diffusivities of $D=0.01,0.02,0.05$, and $0.1 \mathrm{~m}^{2} / \mathrm{s}$, respectively. Background colors labeled (6a to $6 \mathrm{~d}$ ) denote the time periods for which hypocenter distributions are shown in Figure 6. (b) Hypocenter distribution in cluster A. Gray symbols show earthquakes that occurred during the period in (a). Colored circles indicate earthquakes in the short time intervals shown in (c) and (d). Stars represent the locations of pressure sources for the events with corresponding colors. (c, d) Distance versus time plots for the two time periods shown at the top of each figure. Distances were measured from the estimated pressure sources (stars in $\mathbf{( b )}$ ). Dashed lines indicate the theoretical position of the propagating pore pressure front for hydraulic diffusivities of $D=0.1,0.5$, and $1.0 \mathrm{~m}^{2} / \mathrm{s}$, respectively. Red lines indicate the theoretical curve for the optimal $D$ value.

Figure 9. Since $X-S$ times are different for the two stations, it is clear that the $X$-phase is neither the $P$ - or $S$-phase of a successive earthquake. Figure 10 shows seismograms of the two stations for the five earthquake clusters labeled A to $\mathrm{E}$ in Figure 2b. From this figure, we can see that the $X$-phase is commonly observed for all the clusters, but its features depend on both the stations and the clusters; $X-S$ times are different for the two stations, and the relative amplitude of the $X$-phase varies among the clusters. At station N.ANIH, the $X-S$ times are larger for cluster $\mathrm{C}$ than for cluster $\mathrm{A}$, though cluster $\mathrm{C}$ is located closer to the station. This suggests that the seismic waves initially traveled away from the station, then traveled towards the station after scattering/reflection. Therefore, using the spatial variation of $X-S$ times and relative amplitudes, we can estimate the location of scatterers/reflectors. Before performing the calculation, we need to know the wave type of the $X$-phase. Polarization analysis (Jurkevics 1988) indicates that the oscillation of the $X$-phase is horizontal, perpendicular to the source direction, and highly linear; these are the characteristics of $S$-wave behavior. Since the $X$-phase is not a single pulse but a wave train, we interpreted the phase as $S$-to- $S$ scattered waves.

Next, we estimated the location of the scatterers using a method analogous to the source-scanning algorithm (Kao and Shan 2004) in which the amplitude of seismic waves was back-projected onto hypothetical sources to obtain the spatial distribution of 'brightness'. In this study, the location with the highest brightness is considered to be that of the scatterers. For the brightness calculation, we used the bandpass-filtered RMS envelope, which corresponds to obtaining the spatial distribution of seismic energy by projection. We calculated the RMS envelope from the two horizontal components as a vector sum of filtered traces with center frequencies of 4, 8, and $16 \mathrm{~Hz}$. The filter has double octave bands. Figure 11a shows individual and average (stacked) RMS envelopes for cluster A (Figure 2b). Phase $X$ is clearest in 
(a)
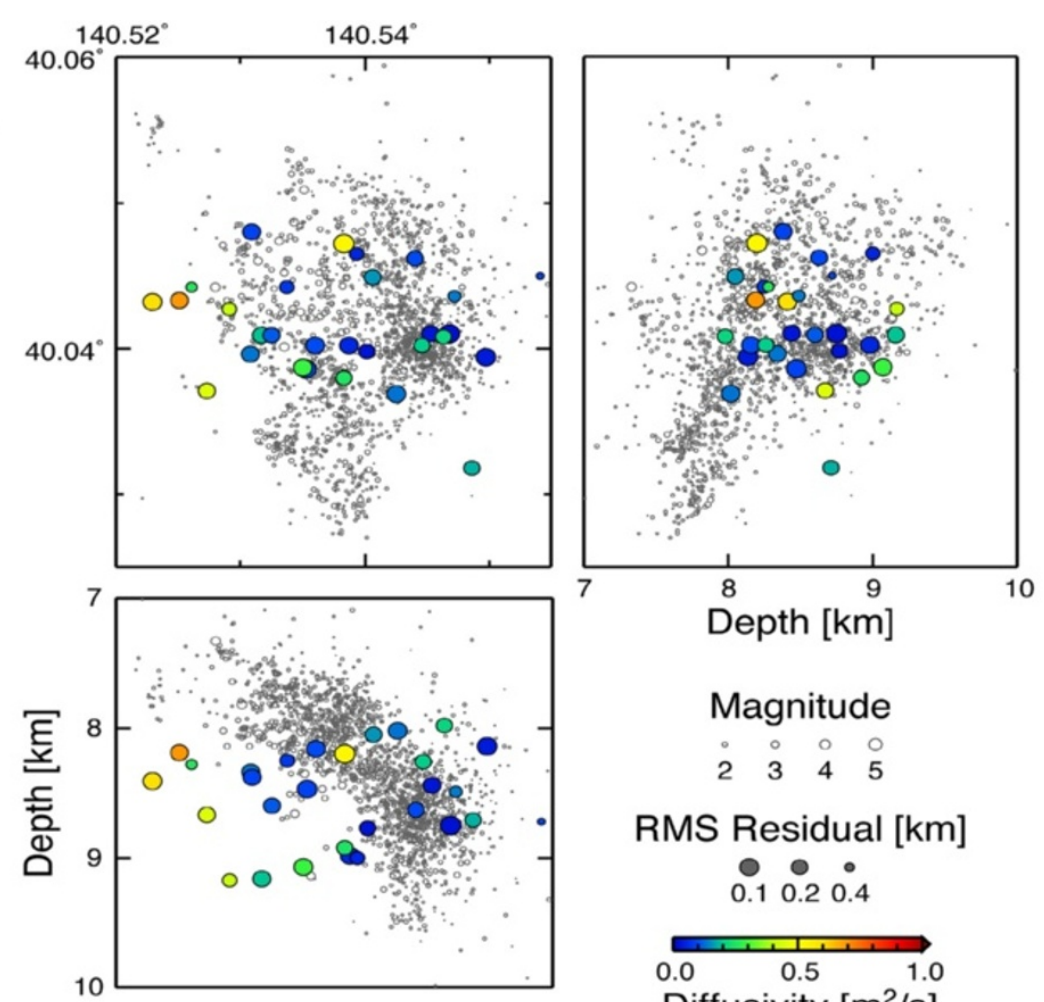

\section{Magnitude}

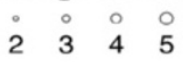

RMS Residual [km]
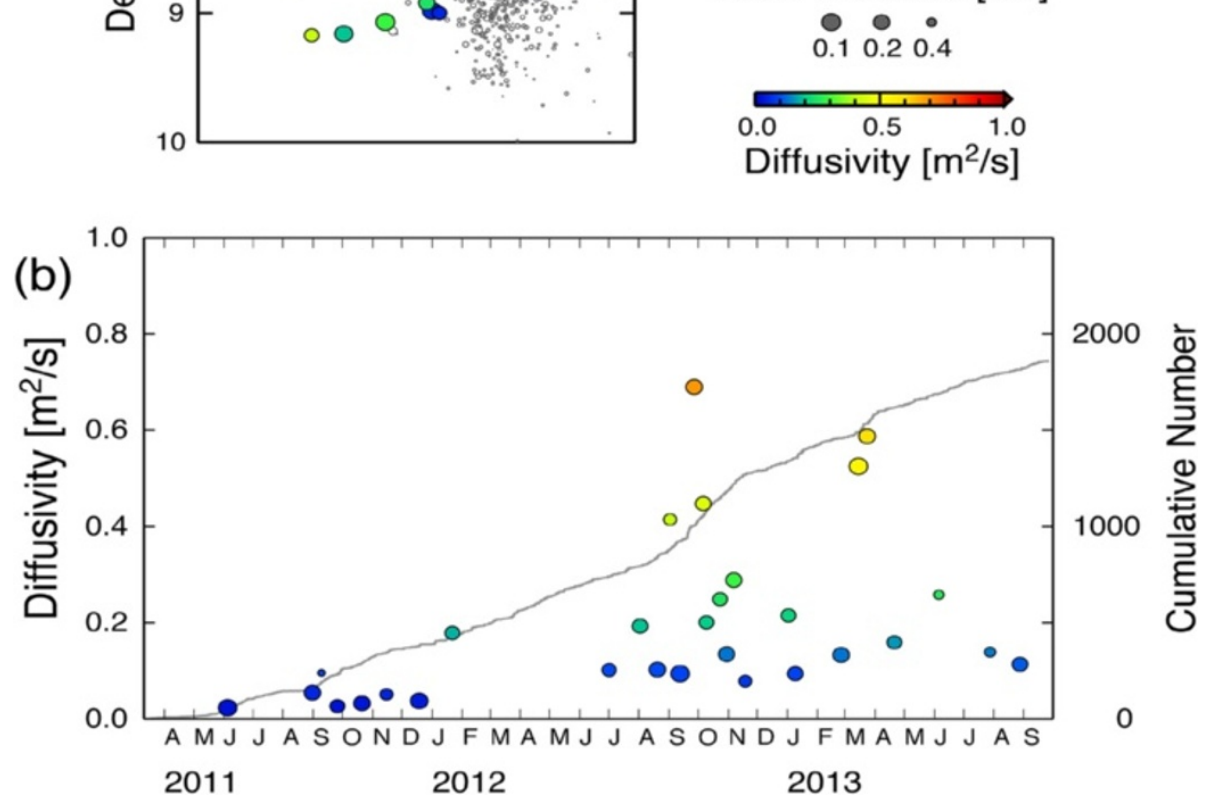

Figure 8 Spatiotemporal variation of hydraulic diffusivities. (a) Spatial distribution of pressure sources estimated by the grid search method. The colors of the circles represent the hydraulic diffusivities. The size of the colored circles is inversely proportional to the RMS residual for the fitting of the diffusion model. Gray symbols are earthquakes that occurred from March 2011 to September 2013. (b) Temporal changes in hydraulic diffusivity. The circles are plotted at the time of pressure increase, as estimated by the grid search. The gray line indicates the cumulative number of earthquakes in cluster $\mathrm{A}$.

the average envelope, particularly at higher frequency ranges. The amplitude of the envelope is largest at the time of arrival of the $S$-wave, then decays gradually with time. Scattered waves $(X)$ are superposed on this general trend. To utilize the amplitude of the $X$ phase, we removed the trend by subtracting the theoretical envelope from the original. We employed a single scattering model (Sato 1977) to calculate the theoretical envelope. The model describes the time variation of scattered energy from random inhomogeneities as

$$
E=C K(t) \exp \left(-\omega t / Q_{C}\right)
$$

where $C$ is the source factor, $K(t)$ is a factor that represent the effect of geometrical spreading, $t$ is the lapse time measured from the earthquake origin time, $\omega$ is 


\section{10/12 3:23:29.90 40.030N 140.540E $7.8 \mathrm{~km}$ M2.1 \\ (a) HR.MAS1-Z}
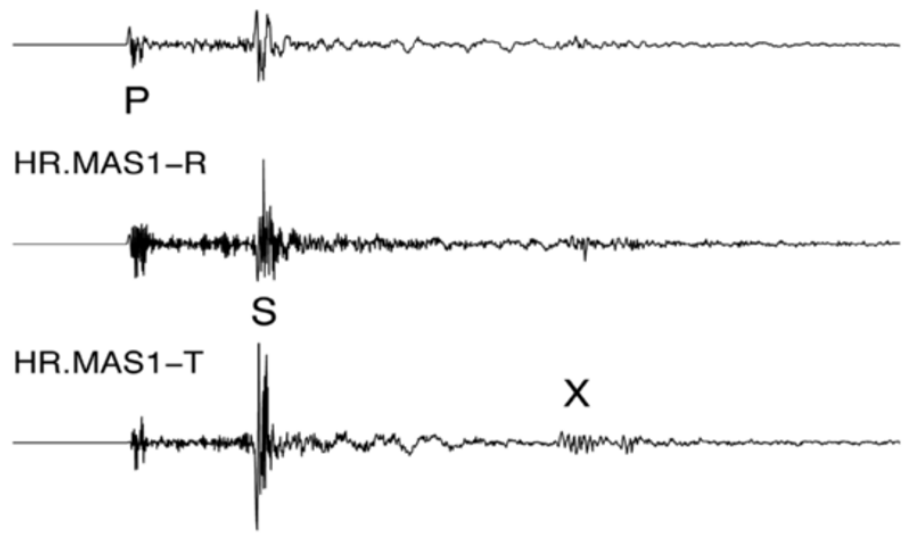

(b) N.ANIH-Z
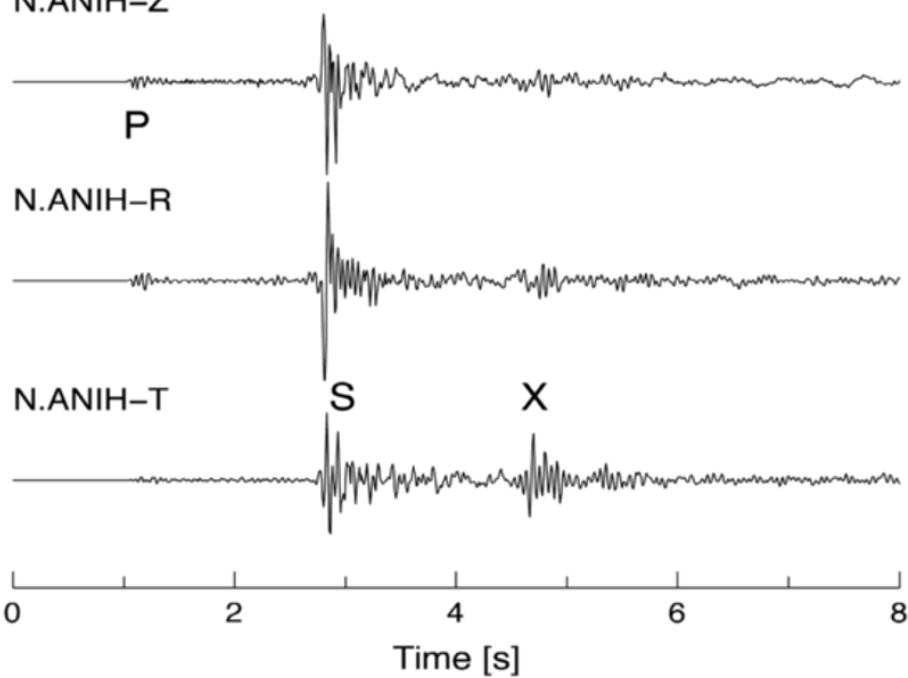

Figure 9 Three-component seismograms from two stations for an earthquake in cluster A. (a) Seismograms from station HR.MAS1. (b) Seismograms from station N.ANIH. The labels $P, S$, and $X$ mark the arrival times of $P$ - and $S$-waves and a phase of unknown origin, respectively. The horizontal components are rotated to show the radial (R) and tangential (T) components. The amplitude is normalized to the maximum of the three components.

the angular frequency, and $Q_{C}$ is the quality factor of the coda wave (coda $Q$ ). We applied the model to a time window with a lapse time greater than twice the $S$-wave travel time. Figure 12 shows examples of the curve fitting for three components and five frequency bands. The scattering model explains the whole temporal decay of amplitude very well. Coda $Q$, which represents the decay rate of the amplitude, has been measured in many regions worldwide and has been discussed in relation to the tectonic activity in the area. The coda $Q$ obtained in this study is consistent with that previously estimated in the Moriyoshi-zan area (Matsumoto and Hasegawa 1989). Figure 11b is a plot of the individual and stacked residual envelopes. The $X$ - phase is the most prominent in the average envelope here as well.

The method of calculating the brightness here is the same as that used by Kosuga (2011) to evaluate the conversion points from hydroacoustic $T$-waves to seismic $T$ waves. The data is the average residual RMS amplitude $A$ as a function of lapse time from the earthquake origin time and observed at $M$ stations for $N$ clusters. By specifying the location of the scatterer, we calculate the travel time $T_{i k j}$ from the $i$-th cluster to the $j$-th station via the $k$-th scatterer. Then, the normalized RMS amplitude $A$ $\left(T_{i k j}\right)$ at lapse time $T_{i k j}$ is squared and summed over $M$ stations and $N$ clusters to obtain a brightness value (energy). 


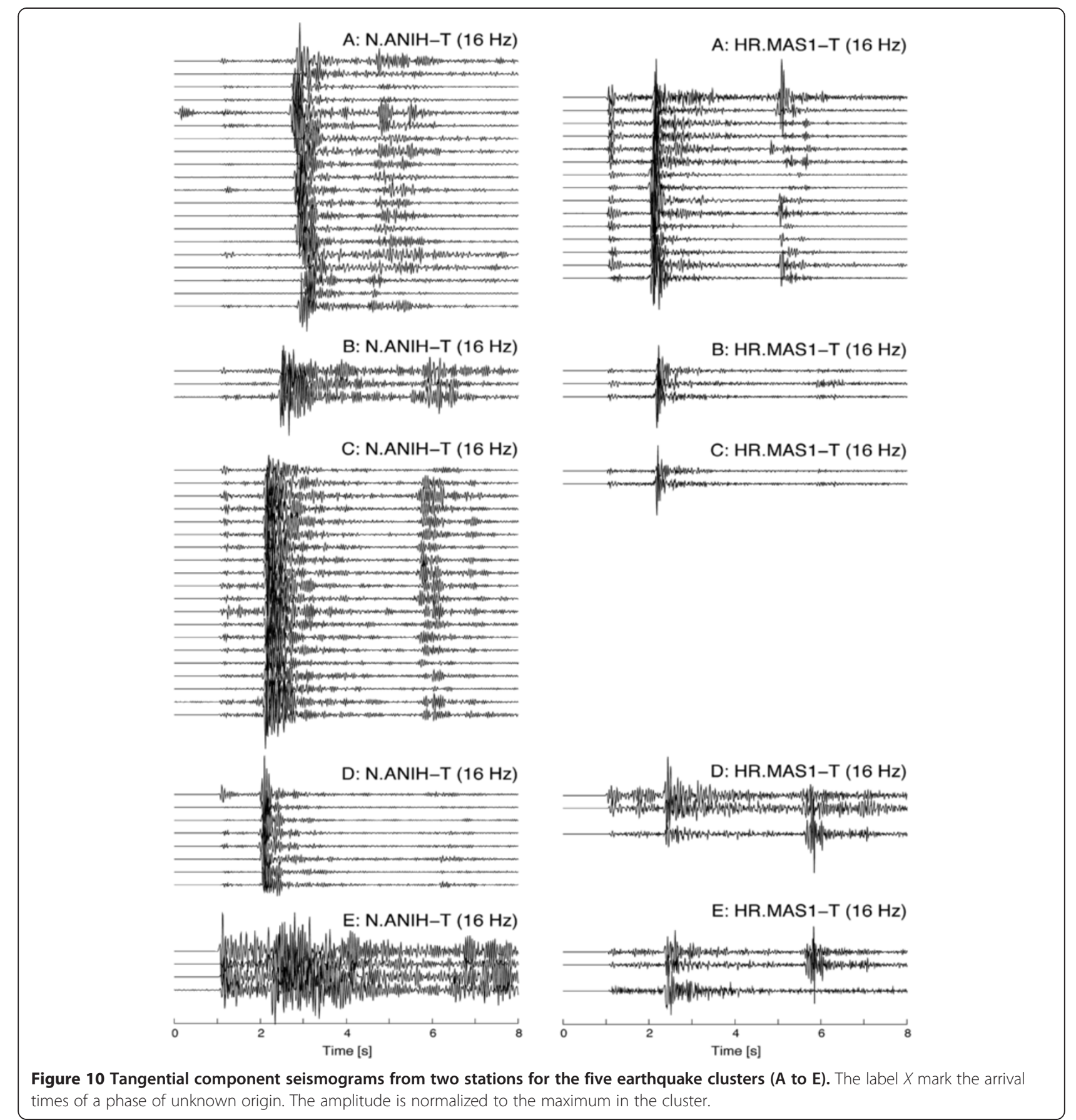

$$
B_{k}=\sum_{i=1}^{N} \sum_{j=1}^{M} A\left(T_{i k j}\right)^{2}
$$

for the $k$-th point scatterer. The average residual RMS waveforms displayed in Figure 11b exhibit large amplitudes in the time window immediately after the arrival of the $S$-wave. Since the scattering model cannot be applied to this window, we muted the amplitude in the window with a length of $2 \mathrm{~s}$. We set the hypothetical source points on equally spaced grid points, in the range $39.9^{\circ}$ to $40.2^{\circ} \mathrm{N}, 140.35^{\circ}$ to $140.7^{\circ} \mathrm{E}$ and 0 to $15 \mathrm{~km}$, covering the entire study area in Figure 2. The spacing of the grid points is $0.005^{\circ}$ and $0.2 \mathrm{~km}$ in the horizontal and vertical directions, respectively. For the calculation of travel times of $S$-to- $S$ scattered waves, we used a velocity structure simplified from that used for hypocenter location. For the calculation of brightness values, we used the 

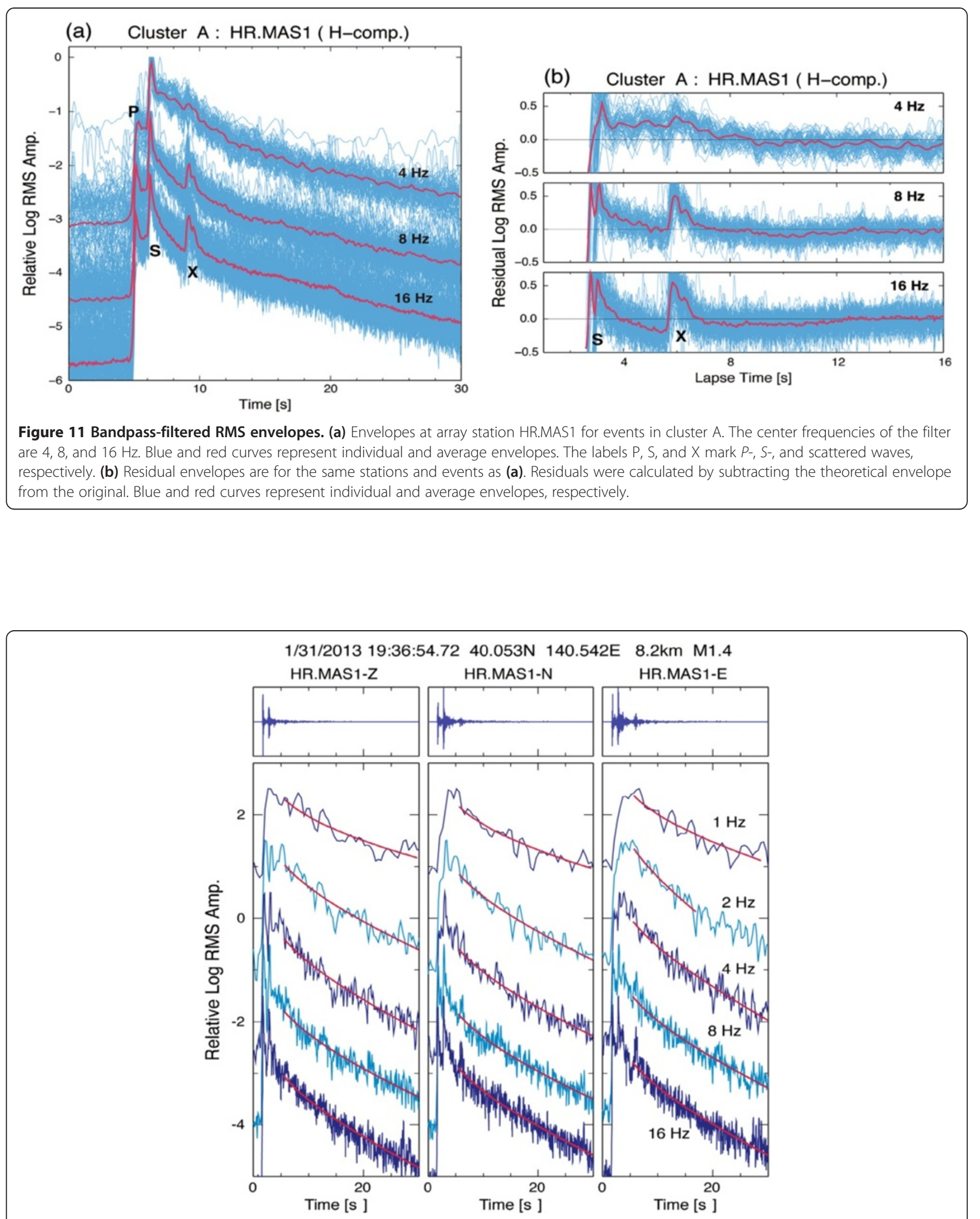

Figure 12 Example fitting of single isotropic scattering model to seismogram envelopes. The raw three-component seismograms are shown at the top. Lower panels show band-pass filtered seismograms and theoretical envelopes (red lines) for five frequency bands: 1, 2, 4, 8 , and $16 \mathrm{~Hz}$ 


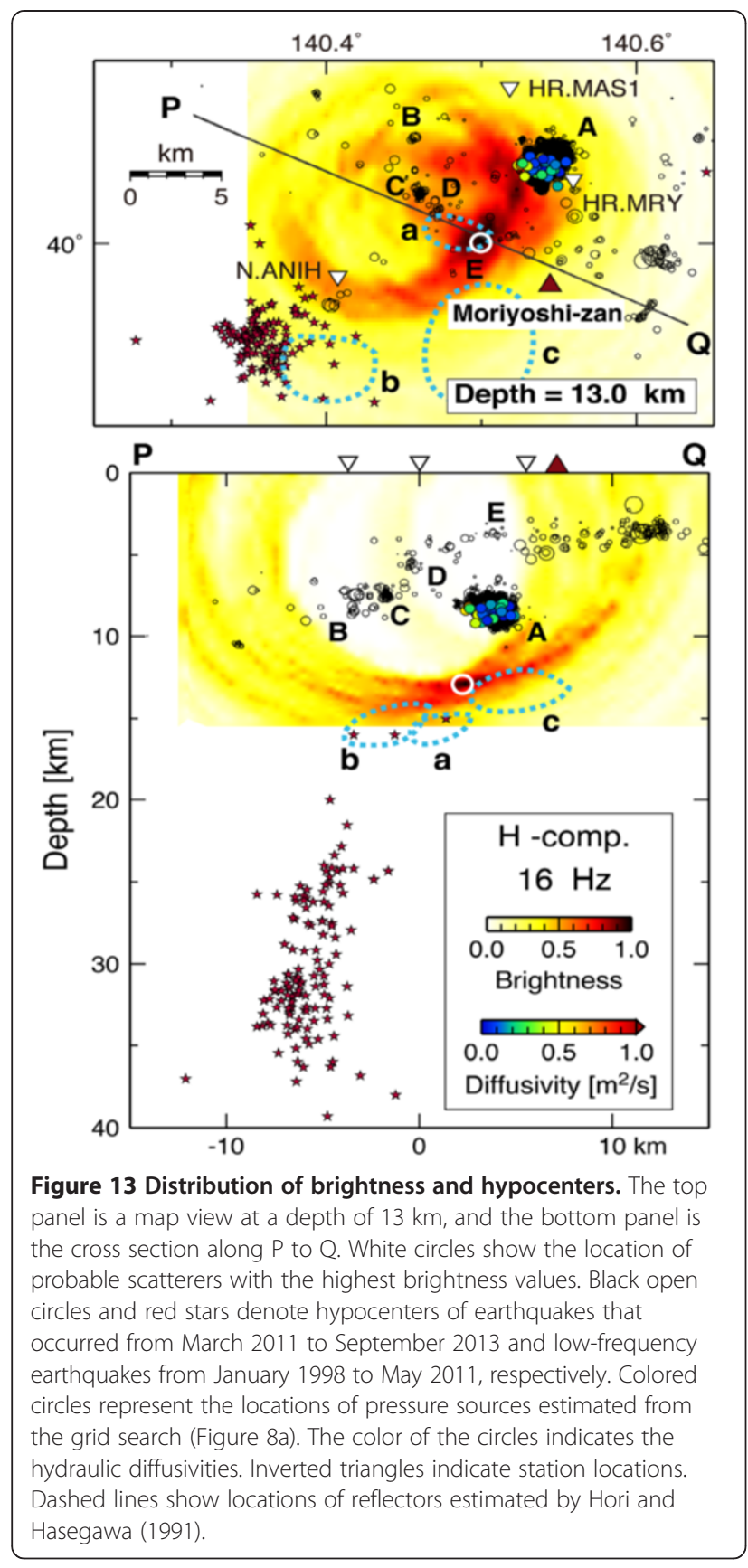

three stations shown in Figure 13 and the five clusters labeled A to E. The effect of attenuation was not considered here because of the short travel distances.

Figure 13 shows the results of the back-projection. The map view is a section at a depth of $13 \mathrm{~km}$, where the calculated brightness has the maximum value. The bottom figure is projected onto the cross section $\mathrm{P}$ to $\mathrm{Q}$. The smearing of the red zones represents isochrones along which the amplitudes of scattered waves were back-projected. Although the resolution of the image is insufficient because of the biased distribution of hypocenters, we think that the size of the scattering zone is smaller than the red zone. The white circle in Figure 13 shows the location with the maximum brightness value. If we consider this to be the location of the scatterers, they are inferred to be located approximately $5 \mathrm{~km}$ northwest of the Moriyoshi-zan volcano, at an approximate depth of $13 \mathrm{~km}$.

\section{Comparison with previous studies}

In this paper, we examine the triggered seismic activity after the Tohoku-oki earthquake in the Moriyoshi-zan area. Okada et al. (2011) also examined seismic activity in the wider Tohoku region and found that some areas of increased seismicity are located above the edge of the low-velocity zone in the lower crust. This led them to suggest that the observed activity is due to heterogeneity in the lower crust and the presence of overpressurized fluid (Miller et al. 2004). According to Okada et al. (2014), the earthquake cluster studied in this paper is also located above the edge of the low-velocity zone beneath the Moriyoshi-zan volcano. Kosuga et al. (2012) reported the coseismic rotation of the stress field in the northern Tohoku region by the Tohoku-oki earthquake. Since the calculated coseismic stress change in the region was smaller than $1 \mathrm{MPa}$ (Yoshida et al. 2012), Terakawa et al. (2013) considered that the pore fluids play an important role in the activation of local seismicity and coseismic stress rotation in the central Akita region. In this study, we provide additional observational data for considering the role of geofluids using hydraulic diffusivity and the locations of scatterers as candidates for geofluid reservoirs.

The remotely triggered seismicity after the 2002 Denali fault earthquake $\left(M_{\mathrm{W}}=7.9\right)$ has been extensively examined both in volcanic and non-volcanic areas. Short-term (hours to days) increases in seismicity were observed in Yellowstone (Husen et al. 2004), Mt. Rainier (Prejean et al. 2004), the Geysers and Coso geothermal fields (Prejean et al. 2004), and Mammoth Mountain, Long Valley Caldera (Johnston et al. 2004). Several researchers have proposed a variety of physical models that might generate remotely triggered earthquakes in the volcanic areas. The models involve changes in crack conductivity and pore fluid pressure in the hydrothermal system (e.g., Brodsky et al. 2003), changes in fluid pressure by the oscillation of bubbles (e.g., Linde et al. 1994; Brodsky et al. 1998), changes in the state of magma bodies (e.g., Linde et al. 1994), and changes in the friction across a fault surface (e.g., Gomberg and Davis 1996; Voisin, 2002). Since the earthquake swarms in Long Valley Caldera and Mount Rainier seem to represent a delayed response to the Denali fault earthquake, Prejean et al. (2004) suggested that earthquakes may be triggered by more than one physical process. Since the Moriyoshi-zan is a Quaternary volcano with no volcanic activity at present, some of the 
above models relating to magma and gas cannot be applied to the area. The resultant models may be related to geofluid or fault properties. Our observation of hypocenter migration and $S$-to- $S$ scattered waves suggest the contribution of geofluids.

We interpreted the hypocenter migration to be the result of the propagation of pore fluid pressure. The hydraulic diffusivity $D$ was $0.01 \mathrm{~m}^{2} / \mathrm{s}$ across the entire investigation period and 0.05 to $0.1 \mathrm{~m}^{2} / \mathrm{s}$ for the initial stage of seismic activity (Figure $7 \mathrm{a}$ ). For shorter time intervals, $D$ values varied from 0.01 to $0.7 \mathrm{~m}^{2} / \mathrm{s}$ and were mostly $<0.4 \mathrm{~m}^{2} / \mathrm{s}$ (Figure 8 ). $D$ values were also estimated by previous studies using natural, induced, and injection-triggered earthquakes. The $D$ values are 0.4 to $7 \mathrm{~m}^{2} / \mathrm{s}$ on the basis of reservoir-induced seismicity (Simpson et al. 1988), $0.5 \mathrm{~m}^{2} / \mathrm{s}$ from water injectioninduced seismicity (Shapiro et al. 1997), and $0.27 \mathrm{~m}^{2} / \mathrm{s}$ (Parotidis et al. 2003) and 0.5 to $1.0 \mathrm{~m}^{2} / \mathrm{s}$ (Yukutake et al. 2011b) from the spatiotemporal distribution of swarm activity. The $D$ values estimated for the Moriyoshi-zan area are considered comparable to those in other regions.

Seismograms from the events in the Moriyoshi-zan area exhibit prominent $S$-to- $S$ scattered waves from the scatterers located approximately $5 \mathrm{~km}$ northwest of the Moriyoshi-zan volcano and at a depth of $13 \mathrm{~km}$ (Figure 13). Hori and Hasegawa (1991) observed a phase similar to the $X$-phase in seismograms from an earthquake swarm in 1982 near the volcano. They interpreted the phase as an $S$-to- $S$ reflected wave and estimated the location of the reflector using travel time data. They estimated several reflectors (dashed lines in Figure 13) from different sets of event-station pairs. The reflector labeled 'a' in Figure 13 is very close to the scatterers estimated in this study. Hence, we propose that the observed scatterer/reflector probably represents the same geofluid reservoir. It is interesting to note that the scatterers found in this study are slightly shallower than the reflector estimated by Hori and Hasegawa (1991). This depth discrepancy may be caused by the difference in the locations of earthquakes and stations and by the different methods and velocity structures used in the two analyses.

The Moriyoshi-zan area is one of the source areas of DLF earthquakes that occur beneath active volcanoes in northeastern Japan (Hasegawa and Yamamoto 1994; Kamaya and Katsumata 2004; Takahashi and Miyamura 2009). The stars in Figure 13 denote the hypocenters of DLF earthquakes in the JMA catalog. The JMA started flagging low-frequency events in their catalog after 1998. The location of the events is approximately $15 \mathrm{~km}$ WSW of the Moriyoshi-zan volcano at a depth range of 20 to $40 \mathrm{~km}$. The observed source area has a vertically elongated shape, which is typical of DLF events in northeastern Japan (Takahashi and Miyamura 2009). The DLF earthquakes that occur well below the elastic- plastic boundary are interpreted as events generated by the activity of geofluids (e.g., Hasegawa and Yamamoto 1994). The upper depth limit of low-frequency earthquakes is close to the depth of geofluid reservoirs, though the location is different in the map view. Based on this assumption, we can imagine the path of a geofluid as follows; the geofluid moves up accompanying DLF earthquakes and accumulates in the middle crust, forming geofluid reservoirs; then, the geofluid moves further up towards the seismogenic zone, if the conditions of fluid migration are fulfilled. Hasegawa et al. $(2005,2012)$ has already proposed a similar idea involving the contribution of geofluid to the generation of large inland earthquakes. Our investigation in this paper supports this idea by providing a detailed study of the activation of local seismicity after the Tohoku-oki earthquake and the distribution of scatterers estimated by back-projection.

If the seismicity was triggered by geofluids, we need to explain why there is no seismicity and no scattering between the reservoir and the pressure sources in Figure 13. As mentioned in the section 'Hypocenter location', the aseismic zone forms a conical shape centered at the volcano. The fluid pathway is located in this aseismic zone; hence, seismicity was not observed. The behavior of scattering is dependent on both the wavelength and the size of the scatterers. In the back-projection analysis, we used envelopes with a predominant frequency of $16 \mathrm{~Hz}$, for which the wavelength is on the order of $100 \mathrm{~m}$. Considering the duration of the $X$-phase was up to $1 \mathrm{~s}$, the reservoir may be assumed to be an aggregate of scatterers of this size. Furthermore, the size of the pathway from the reservoir may be considerably smaller and invisible at frequencies equal to or lower than $16 \mathrm{~Hz}$. However, direct evidence is lacking for the existence of geofluid in the postulated reservoir. A plausible approach to the problem is a close examination of scattered phases and their temporal variation. In Figure 10, we aligned seismograms on the catalog $P$-wave picks, which is not adequate for that purpose. The alignment and stacking of waveforms of similar earthquakes based on the CC picks may be useful, as Rowe et al. (2004) and DeShon et al. (2007) have shown. Thus, increasing the spatial resolution of hypocenters and pressure sources as well as the scattering structure near the geofluid reservoir would be the next step of this study, using waveforms of smaller earthquakes we have not analyzed in this paper.

\section{Conclusions}

We examined the triggered seismic activity in the Moriyoshi-zan area after the Tohoku-oki earthquake based on hypocenters relocated using the combined data of permanent and temporary observations and the hypoDD location technique. We interpreted the 
spatiotemporal variation in seismic activity as the result of the migration of fluid pressure. We estimated a hydraulic diffusivity of 0.01 to $0.7 \mathrm{~m}^{2} / \mathrm{s}$, which is comparable to other regions. For shorter time periods, we found that the diffusivity increased with time. We observed prominent $S$-to-S scattered waves and estimated the locations of scatterers using the back-projection method. These scatterers were located approximately $5 \mathrm{~km}$ northwest of the Moriyoshi-zan volcano, at a depth of $13 \mathrm{~km}$. This depth is close to the upper limit of the DLF earthquakes, which are thought to be related to geofluids. Thus, we regard the scatterers as reservoirs of geofluids that rise from the uppermost mantle accompanying low-frequency earthquakes and as the sources of overpressure fluids that caused the migration of seismicity.

\section{Competing interests}

The author declares that he has no competing interests.

\begin{abstract}
Acknowledgements
I used hypocentral parameters and phase picks from the JMA catalog, which was prepared by the JMA and the Ministry of Education, Culture, Sports, Science, and Technology in Japan. The catalog hypocenters were determined using data from JMA, NIED, Hirosaki University, Tohoku University, Hokkaido University, University of Tokyo, and Aomori Prefecture. I thank the National Research Institute for Earth Science and Disaster Prevention (NIED) and Tohoku University for providing waveform data. I thank Kazuma Masukawa, Masaaki Chiba, and Katsuhito Sato of Hirosaki University for their contribution to the observations and the acquisition of data. Constructive comments from two anonymous reviewers were helpful in revising the manuscript. All figures were drawn using the Generic Mapping Tools (GMT) developed by Wessel and Smith (1998). This work was supported by JSPS KAKENHI Grant Number 21109002
\end{abstract}

Received: 22 November 2013 Accepted: 15 July 2014

Published: 25 July 2014

\section{References}

Brodsky EE, Sturtevant B, Kanamori H (1998) Earthquakes, volcanoes, and rectified diffusion. J Geophys Res 103:23827-23838

Brodsky EE, Roeloffs E, Woodcock D, Gall I, Manga M (2003) A mechanism for sustained groundwater pressure changes induced by distant earthquakes. J Geophys Res 108, doi:10.1029/2002JB002321

DeShon HR, Thurber CH, Rowe CA (2007) High-precision earthquake location and three-dimensional $P$ wave velocity determination at Redoubt volcano, Alaska. J Geophys Res 112:B07312, doi:10.1029/2006JB004751

Gomberg J, Davis S (1996) Stress/strain changes and triggered seismicity at the Geysers, California. J Geophys Res 101:733-749

Got JL, Frechet J, Klein FW (1994) Deep fault plane geometry inferred from multiplet relative relocation beneath the south flank of Kilauea. J Geophys Res 99:15375-15386

Hasegawa A, Yamamoto A (1994) Deep, low-frequency microearthquakes in or around seismic low-velocity zones beneath active volcanoes in northeastern Japan. Tectonophys 233:233-252

Hasegawa A, Umino N, Takagi A (1978) Double-planed structure of the deep seismic zone in the northeastern Japan arc. Tectonophys 47:43-58

Hasegawa A, Nakajima J, Umino N, Miura S (2005) Deep structure of the northeastern Japan arc and its implications for crustal deformation and shallow seismic activity. Tectonophys 403:59-75, doi:10.1016/j.tecto.2005.03.018

Hasegawa A, Nakajima J, Uchida N, Yanada T, Okada T, Zhao D, Matsuzawa T, Umino N (2012) Mechanism generating earthquakes in subduction zones: Vital role of geofluids in earthquake generation. J Geography 121:128-160 (in Japanese with English abstract)

Hirose F, Miyaoka K, Hayashimoto N, Yamazaki T, Nakamura M (2011) Outline of the 2011 off the Pacific coast of Tohoku Earthquake $\left(M_{w}\right.$ 9.0)—seismicity: foreshocks, mainshock, aftershocks, and induced activity-. Earth Planets Space 63:513-518, doi:10.5047/eps.2011.05.019

Hori S, Hasegawa A (1991) Location of a mid-crustal magma body beneath Mt. Moriyoshi, northern Akita prefecture, as estimated from reflected SxS phases. Zisin (J Seismol Soc Japan) 44:39-48 (in Japanese with English abstract)

Husen S, Wiemer S, Smith RB (2004) Remotely triggered seismicity in the Yellowstone National Park region by the 2002 Mw 7.9 Denali Fault earthquake, Alaska. Bull Seismol Soc Am 94:S317-S331, doi:10.1785/0120040618

Imanishi K, Ando R, Kuwahara Y (2012) Unusual shallow normal-faulting earthquake sequence in compressional northeast Japan activated after the 2011 off the Pacific coast of Tohoku earthquake. Geophys Res Lett 39:L09306, doi:10.1029/2012GL051491

Ishibe T, Shimazaki K, Satake K, Tsuruoka H (2011) Change in seismicity beneath the Tokyo metropolitan area due to the 2011 off the Pacific coast of Tohoku Earthquake. Earth Planets Space 63:731-735, doi:10.5047/eps.2011.06.001

Ito A (1985) High resolution relative hypocenters of similar earthquakes by cross-spectral analysis method. J Phys Earth 33:279-294

Johnston MJS, Prejean SG, Hill DP (2004) Triggered deformation and seismic activity under Mammoth Mountain in Long Valley Caldera by the 3 November 2002 Mw 7.9 Denali Fault earthquake. Bull Seismol Soc Am 94:S360-S369, doi:10.1785/0120040603

Jurkevics A (1988) Polarization analysis of three-component array data. Bull Seismol Soc Am 78:1725-1743

Kamaya N, Katsumata A (2004) Low-frequency events away from volcanoes in the Japan Islands. Zisin (J Seismol Soc Japan) 57:11-28 (in Japanese with English abstract)

Kao H, Shan S-J (2004) The source-scanning algorithm: mapping the distribution of seismic sources in time and space. Geophys J Int 157:589-594, doi:10.1111/j.1365-246X.2004.02276.x

Kato A, Sakai S, Obara K (2011) A normal-faulting seismic sequence triggered by the 2011 off the Pacific coast of Tohoku Earthquake: wholesale stress regime changes in the upper plate. Earth Planets Space 63:745-748, doi:10.5047/eps.2011.06.014

Kosuga M (2011) Localization of T-wave energy on land revealed by a dense seismic network in Japan. Geophys J Int 187:338-354, doi:10.1111/j.1365-246X.2011.05143.X

Kosuga M, Watanabe K, Hashimoto K, Kasai H (2012) Seismicity in the northern part of Tohoku district induced by the 2011 Off the Pacific coast of Tohoku Earthquake. Zisin (J Seismol Soc Japan) 65:69-83 (in Japanese with English abstract)

Linde AT, Sacks IS, Johnston MJS, Hill DP, Bilham RG (1994) Increasing pressure from rising bubbles as a mechanism for remotely triggered seismicity. Nature 371:408-410

Matsumoto S, Hasegawa A (1989) Two-dimensional coda Q structure beneath Tohoku, NE Japan. Geophys J Int 99:101-108

Miller SA, Colletini C, Chairaluce L, Cocco M, Marchi M, Kaus BJP (2004) Aftershocks driven by a high-pressure $\mathrm{CO}_{2}$ source at depth. Nature 427:724-727, doi:10.1038/nature02251

Miyazawa M (2011) Propagation of an earthquake triggering front from the 2011 Tohoku-Oki earthquake. Geophys Res Lett 38:L23307, doi:10.1029/2011GL049795

Miyazawa M (2012) Detection of seismic events triggered by $P$-waves from the 2011 Tohoku-Oki earthquake. Earth Planets Space 64:1223-1229, doi:10.5047/eps.2012.07.003

Nakagawa M (1983) Geology and petrology of Moriyoshi volcano. J Mineral Petrol Eco Geol 78:197-210 (in Japanese with English abstract)

Okada T, Yoshida K, Ueki S, Nakajima J, Uchida N, Matsuzawa T, Umino N, Hasegawa A, Group for the aftershock observations of the 2011 off the Pacific coast of Tohoku Earthquake (2011) Shallow inland earthquakes in NE Japan possibly triggered by the 2011 off the Pacific coast of Tohoku Earthquake. Earth Planets Space 63:749-754, doi:10.5047/eps.2011.06.027

Okada T, Matsuzawa T, Umino N, Takahashi H, Yamada T, Kosuga M, Takeda T, Kato A, Igarashi T, Obara K, Sakai S, Saiga A, lidaka T, Iwasaki T, Hirata N, Tsumura N, Yamanaka Y, Terakawa T, Nakamichi H, Okuda T, Horikawa S, Katao H, Miura T, Kubo A, Matsushima T, Goto K, Miyamachi H (2014) Hypocenter migration and crustal seismic velocity distribution observed for the inland earthquake swarms induced by the 2011 Tohoku-Oki earthquake in NE Japan: implications for crustal fluid distribution and crustal permeability. Geofluids, in press

Parotidis M, Rothert E, Shapiro SA (2003) Pore-pressure diffusion: a possible triggering mechanism for the earthquake swarms 2000 in Vogtland/NW-Bohemia, central Europe. Geophys Res Lett 30:2075, doi:10.1029/2003GL018110 
Poupinet G, Ellsworth WL, Frechet J (1984) Monitoring velocity variations in the crust using earthquake doublets: an application to the Calaveras fault, California. J Geophys Res 89(B7):5719-5731

Prejean SG, Hill DP, Brodsky EE, Hough SE, Johnston MJS, Malone SD, Oppenheimer DH, Pitt AM, Richards-Dinger KB (2004) Remotely triggered seismicity on the United States west coast following the Mw 7.9 Denali Fault earthquake. Bull Seismol Soc Am 94:S348-S359, doi:10.1785/0120040610

Rowe CA, Aster RC, Borchers B, Young CJ (2002a) An automatic, adaptive algorithm for refining phase picks in large seismic data sets. Bull Seismol Soc Am 92:1660-1674

Rowe CA, Aster RC, Phillips WS, Jones RH, Borchers B, Fehler MC (2002b) Using automated, high-precision repicking to improve delineation of microseismic structures at the Soultz geothermal reservoir. Pure Appl Geophys 159:563-596

Rowe CA, Thurber CH, White RA (2004) Dome growth behavior at Soufriere Hills Volcano, Montserrat, revealed by relocation of volcanic event swarms, 1995-1996. J Volcanol Geotherm Res 134:199-221, doi:10.1016/j.jvolgeores.2004.01.008

Sato H (1977) Energy propagation including scattering effects: single isotropic scattering approximation. J Phys Earth 25:27-41

Shapiro SA, Huenges E, Borm G (1997) Estimating the crust permeability from fluid-injection-induced seismic emission at the KTB site. Geophys J Int 131:F15-F18, doi:10.1111/j.1365-246X.1997.tb01215.x

Simpson DW, Leith WS, Scholz CH (1988) Two types of reservoir-induced seismicity. Bull Seismol Soc Am 78:2025-2040

Takahashi H, Miyamura J (2009) Deep low-frequency earthquakes occurring in Japanese Islands. Geophys Bull Hokkaido Univ 72:177-190 (in Japanese with English abstract)

Terakawa T, Hashimoto C, Matsu'ura M (2013) Changes in seismic activity following the 2011 Tohoku-oki earthquake: effects of pore fluid pressure. Earth Planet Sci Lett 365:17-24, doi:10.1016/j.epsl.2013.01.017

Voisin C (2002) Dynamic triggering of earthquakes: the nonlinear slip dependent friction case. J Geophys Res 107:2356, doi:10.1029/2001 JB001121

Waldhauser F, Ellsworth WL (2000) A double-difference earthquake location algorithm: method and application to the northern Hayward fault, California. Bull Seismol Soc Am 90:1353-1368

Wessel P, Smith WHF (1998) New, improved version of the Generic Mapping Tools released. Eos Trans AGU 79:579

Wolfe CJ (2002) On the mathematics of using difference operators to relocate earthquakes. Bull Seismol Soc Am 92:2879-2892

Yoshida K, Hasegawa A, Okada T, linuma T, Ito Y, Asano Y (2012) Stress before and after the 2011 great Tohoku-oki earthquake and induced earthquakes in inland areas of eastern Japan. Geophys Res Lett 39:L03302, doi:10.1029/2011GL049729

Yukutake Y, Honda R, Harada M, Aketagawa T, Ito H, Yoshida A (2011 1a) Remotely-triggered seismicity in the Hakone volcano following the 2011 off the Pacific coast of Tohoku Earthquake. Earth Planets Space 63:737-740, doi:10.5047/eps.2011.05.004

Yukutake Y, Ito H, Honda R, Harada M, Tanada T, Yoshida A (2011 b) Fluid-induced swarm earthquake sequence revealed by precisely determined hypocenters and focal mechanisms in the 2009 activity at Hakone volcano, Japan. J Geophys Res 116:B04308, doi:10.1029/2010JB008036

Zhang H, Thurber CH (2003) Double-difference tomography: the method and its application to the Hayward fault, California. Bull Seismol Soc Am 93:1875-1889

doi:10.1186/1880-5981-66-77

Cite this article as: Kosuga: Seismic activity near the Moriyoshi-zan volcano in Akita Prefecture, northeastern Japan: implications for geofluid migration and a midcrustal geofluid reservoir. Earth, Planets and Space 2014 66:77.

\section{Submit your manuscript to a SpringerOpen ${ }^{\circ}$ journal and benefit from:}

- Convenient online submission

- Rigorous peer review

- Immediate publication on acceptance

- Open access: articles freely available online

- High visibility within the field

- Retaining the copyright to your article

Submit your next manuscript at $\gg$ springeropen.com 